\title{
Possession and Cliticization in Iquito
}

\author{
MARK C. BROWN \\ University of Texas at Austin
}

\section{Goals and Language Background}

This paper presents some unusual distributional data about the possessive construction in Iquito, together with one analysis that accounts for the data. I argue that possessums in Iquito behave much like clitics. However, I would reject any notion that a morpheme must either be a clitic or a free form, or either a clitic or an affix, as if one had dichotomies to choose from. Instead, I assume that what we actually see in language is a continuum or cline from free form to clitic to affix (Brown 2004a), and I argue that Iquito possessums occupy an intermediate status between a free form and a clitic.

Iquito (Zaparoan) is spoken by about 26 individuals in a small community located in Amazonian Peru. This paper presents data from two summers of my fieldwork with the Iquito people as part of the Iquito Language Documentation and Revitalization Project.

\section{Basic Iquito Possession}

Basic Iquito possession is illustrated in examples (1) and (2). In every example in this paper, the possessor is italicized and the possessum is underlined. As shown in (1) and (2), there is no special morphology to indicate that one has possession. Instead, possession is indicated simply by a sequence of two nouns. Interestingly, the relative order of the possessor and possessum nouns reverses depending on whether a determiner is present in the construction. When a determiner is present, the possessum occurs first, and the possessor second. ${ }^{1}$

(1) kinikikurahina iipi saawirika $i k^{w}$ aniwiya [DET POSSESSUM POSSESSOR]

ki- niki -kura -hina iipi saawiri-ka $\mathrm{ik}^{\mathrm{w}}$ ani-wiya

1S- see -PSR -LES DET.Anim.PL machete-PL man -PL

'I have seen those men's machetes.'

\footnotetext{
${ }^{1}$ Abbreviations: $1 \mathrm{~S}=1$ st person singular; Anim = animate; $\mathrm{CMP}=$ completive aspect; $\mathrm{COP}=$ copulative; DET = determiner; DLS = locative; INC = incompletive aspect; IRR = irrealis; LES = ?; $\mathrm{MOT}=$ in front of; $\mathrm{PL}=$ plural; $\mathrm{PSR}=$ recent past.
} 
(2) kimiiyaa $i k^{w}$ ani $\underline{\text { saawiri }}$

ki- mii -yaa $\mathrm{ik}^{\mathrm{w}}$ ani saawiri

[POSSESSOR POSSESSUM]

1S- have-INC man machete

'I have [a] man's machete.'

In example (1), the possessum is saawirika, and it occurs before the possessor, which is ikwaniwiya. When the determiner is absent, as in (2), the possessor occurs first, and the possessum occurs second. In (2), the possessor is ikwani and occurs before the possessum, which is saawiri. One can now make a generalization about possession in Iquito data:

(3) Generalization \#1: The possessum occurs just after the determiner, or, absent a determiner, just after the possessor.

Notice also that in (1), we have a discontinuous phrase. The determiner is actually modifying the possessor, not the possessum. This is the case for two reasons. First, as one can see from the chart in (4), this form of the determiner is plural and plus animate:

The Iquito Determiners

\begin{tabular}{|l|l|l|}
\hline Iquito Morpheme & Translation & Special Significance \\
\hline iina & this/these, that/those & \\
\hline iipi & these, those & $+\mathrm{PL},+$ Animate \\
\hline iimi & these, those & $+\mathrm{PL},-$ Animate \\
\hline
\end{tabular}

Thus, this determiner cannot modify an inanimate noun such as 'machetes', the possessum. Instead, the plural determiners must agree in animacy with the noun they modify, and the only noun that is animate in this phrase is the possessor. Second, native speaker back translations consistently say the determiner is modifying the possessor, rather than the possessum, as indicated in the glosses. That is, native speakers never say in their back translations something like, "these machetes of the men." Moreover, attempts to directly modify the possessum with a determiner result in ungrammatical sentences, as seen in (5).

$$
\begin{aligned}
& \text { *iina káhinani iina misahi maki-i } \\
& \text { DET domesticated.animal DET woman sleep-INC } \\
& \text { 'This dog of that woman is sleeping.' }
\end{aligned}
$$

In addition, one can also never directly modify the possessum with its own adjectival modifiers:

(6) *ki- niki-ki Juana niyiini suwaani

1S-see -CMP Juana baby pretty

'I have seen Juana's beautiful baby.' 
The sentence in (6) is bad because the possessum cannot be directly modified with an adjective. Instead, native speakers must employ periphrastic constructions to modify the possessum indirectly, as shown in (7) and (8).

$$
\begin{aligned}
& \text { ki-niki-ki Juana niyiini. Suwaani tii } \\
& \text { 1S-see-CMP Juana baby pretty COP } \\
& \text { 'I have seen Juana's baby; it is beautiful.' }
\end{aligned}
$$

$$
\begin{aligned}
& \text { ki-niki -ki ina miyaara umaana, iina kájinani amiyakiyaana } \\
& \text { 1S-see -CMP DET dog big DET dom. animal hunter } \\
& \text { 'I saw this big dog, this hunter's dog.' }
\end{aligned}
$$

In (7) there are two entirely separate sentences. In (8) there is a fragment at the end of the sentence. For comparison, a simple noun phrase without possession could normally have an adjectival modifier either before or after the noun, while the determiner always precedes the noun:

$$
\begin{aligned}
& \text { ki-niki -ki ina (umaana) miyaara (umaana) } \\
& \text { 1S-see -CMP DET big dog big } \\
& \text { 'I saw this (big) dog.' }
\end{aligned}
$$

In addition to the discontinuity seen in (1), these determiners are also involved in another type of discontinuity, which I believe sheds light on the nature of the possessive construction. In irrealis ${ }^{2}$ constructions, there is a position immediately in front of the verb in which the speaker, apparently for discursive reasons, can place various types of material, such as a direct object, a nominal adjunct, or a time adverb. When a speaker chooses to place a direct object in this location, one has a discontinuous phrase if the direct object is modified by a determiner, as in (10), or no discontinuous phrase if the determiner is absent, as in (11).

$$
\begin{aligned}
& \text { a. amikaaka ki iina rikatahuuya-rił iimina minani } \\
& \text { Tomorrow 1S DET fix -IRR canoe black } \\
& \text { 'Tomorrow I will fix this black canoe.' } \\
& \text { b. amikaaka ki iimi rikatahuuyar-rii kumi iimina } \\
& \text { Tomorrow 1S DET fix -IRR two canoe } \\
& \text { 'Tomorrow I will fix those two canoes.' }
\end{aligned}
$$

\footnotetext{
${ }^{2}$ Irrealis constructions are used for the future, conditionals, hypotheticals, wishes, and infinitival clauses. For a detailed description of the irrealis construction, including the nature of this position in front of the verb and the distribution of various arguments and adjuncts, see Brown (2004b).
} 
(11) a. amikaaka ki iimina minani mii-rii Tomorrow $1 \mathrm{~S}$ canoe black make-IRR 'Tomorrow I will make [a] black canoe.'

b. amikaaka ki kumi iimina rikatahuuyar-rii Tomorrow 1S two canoe fix -IRR 'Tomorrow I will fix those two canoes.'

In (10a) and (10b), the determiner occurs to the left of the verb, which is rikatahuuyariz, while the noun and all of the noun's complements occur to the right of the verb. In the case of the direct objects in (11a) and (11b), there is no determiner and now the noun and all of its complements must occur on the left side of the verb. The contrast seen between (10) and (11) may be evidence for a movement analysis of the demonstrative determiner. That is, either a bare NP moves to the new position in the case where there is no determiner, or if there is a determiner, then only the determiner moves to the new position and the NP constituent is left in its base-generated position.

The distribution seen in (10) and (11) is obligatory. For example, sentence (12) is bad because the adjective occurs on the wrong side of the verb:

*amikaaka ki iimina mii-rii minani Tomorrow 1S canoe make-IRR black

'Tomorrow I will make [a] black canoe.'
*amikaaka ki iina minani rikatahuuya-rì iimina Tomorrow 1S DET black fix -IRR canoe 'Tomorrow I will fix this black canoe.'

Similarly, example (13) is bad because the adjective cannot occur on the left side of the verb with the determiner when the noun is on the right side. This data allows one to make a second generalization about the data:

(14) Generalization \#2: In irrealis constructions, a noun and its complements must remain contiguous.

A good question to ask at this point is, what happens when one has a possessive construction in these types of sentences? Where does the possessor or possessum occur in relation to the other noun in its phrase?

\footnotetext{
$[\mathrm{Adv}][\mathrm{Subj}][\mathrm{Det}][\underline{\mathrm{Pm}}][\mathrm{Verb}][\mathrm{Pr}]$ amikaaka ki iipi nasi aniiruu -rii $i k^{w}$ aniwiya Tomorrow 1S DET.P1.Anim garden to.clear-IRR men 'Tomorrow I will clear these men's garden.'
} 
amikaaka ki iina iimina rikatahuu-rii $i k^{w}$ ani (umaana)

Tomorrow 1S DET canoe fix -IRR man big

'Tomorrow I will fix this (big) man's canoe.'

*amikaaka ki iina iimina $i k^{w}$ ani rikatahuu-rii

Tomorrow 1S DET canoe man fix -IRR

'Tomorrow I will fix this man's canoe.'

As one can see in example (15), when the direct object phrase has a determiner, the possessum must occur on the left of the verb. The possessum in this case is nasi 'garden', and the possessor is ikwaniwiya 'men'. This phrase is discontinuous because the main verb intervenes between the possessum and possessor. The determiner, once more, is modifying the possessor, which is the last word in the sentence, rather than the possessum, which I know because of the animacy agreement and the speaker's back translations. Example (16) shows the same thing as (15). Example (17) is ungrammatical because this discontinuity over the verb is obligatory. The possessor, ikwani, cannot occur on the left side of the verb.

\section{An Analysis Treating the Possessum as a Clitic}

So how does possession work in Iquito? What does this data show us? One of the hallmark signs of a clitic is if one can show that it actually is bound to a phrase. In a well-known example, English possessive 's is bound to the possessor noun phrase. One can make a single accurate and succinct generalization that the English possessive 's must, phonologically, appear at the right edge of the possessor noun phrase, as illustrated by the examples in (18).
a. (The king's) crown.
b. (The king of England's) crown.
c. (The king whom I had tea with's) crown.

Thus, one can correctly predict the location of the English possessive 's with one succinct generalization.

I can make a similarly accurate and succinct generalization for possession in Iquito, which is that the Iquito possessum must occur immediately after the phrasal head. For noun phrases that have a determiner, the phrasal head is the determiner (Abney 1987). For noun phrases that have no determiner present, the bare possessor noun is the phrasal head, following work by Matthewson (1998) and Wiltschko (2003).

(19) Generalization \#3: The possessum in Iquito occurs immediately after the phrasal head.

- For phrases with a determiner, the determiner is the head. (Abney 1987) 
- For phrases without a determiner, there is no null DP, so the bare noun is the head. (Matthewson 1988, Wiltschko 2003) ${ }^{3}$

Generalization \#3 accounts for the distribution in (1) and (2). For example, it would not be unusual for a clitic to occur in the middle of a phrase.

It's also important to notice how the determiner is intimately involved in creating these peculiar distributions. For example, in the irrealis constructions, it seems to occur before the verb in lieu of the whole NP occurring in that position. It is almost as if the determiner can represent the entire noun phrase. The data in (10) seems to indicate that a determiner is uniquely capable of being separated from its nominal complement. If my thesis that a possessum is a clitic-like element bound to the phrasal head and the determiner is the head of a noun phrase is correct, then the distribution seen in (15) is what one would expect. The possessum must occur on the left side of the verb with the determiner, because it is bound to the phrasal head, and must occur together with the phrasal head.

Another property common to clitics is some sort of reduced phonological status. For example, a clitic might not be stressable or pronounceable apart from the word it is bound to. Although preliminary stress data does indicate that Iquito possessums are both stressable and independently pronounceable, the ability to receive stress and be pronounced separately may have more to do with the morpheme's size than its word class. For example, Iquito has a number of adpositions which are listed in (20).

\begin{tabular}{|c|c|}
\hline Adposition & Gloss \\
\hline akuhi & by motive of; in front of \\
\hline karikuma & underneath \\
\hline iiku & owing to (involuntary causation) \\
\hline iikura & owing to (voluntary causation) \\
\hline iira & benefactive \\
\hline hata & accompaniment; instrumental \\
\hline hina & to (destination) \\
\hline niłhina & on top of \\
\hline sirikumahi & to the side of \\
\hline
\end{tabular}

\footnotetext{
${ }^{3}$ This generalization assumes the possessor is the head of the entire possessive construction, rather than the possessum. Other analyses have also argued for an analysis in which the possessor heads the possessum. Other languages have also been argued to have a possessor head the possessive construction, such as Hungarian (Szabolcsi 1994), and others have argued for a functional possessor projection that dominates the possessum, even though the possessum is still the semantic head (Delsing 1998).
} 
These adpositions function to introduce nominal adjuncts into a sentence. Interestingly, these adpositions have exactly the same distribution as the possessum. That is, they occur immediately after the determiner, or if the determiner is absent, immediately after the noun, as shown by (21) and (22):

$\mathrm{k}^{\mathrm{w}}$ asa-ki iina akuhi $\mathrm{ik}^{\mathrm{w}}$ ani

1S-eat-CMP Det in.front.of man

'I ate in front of this man.'

$$
\begin{aligned}
& \mathrm{k}^{\mathrm{w}} \text { asa-ki } \mathrm{ik}^{\mathrm{w}} \text { ani } \frac{\text { akuhi }}{\mathrm{MOT}} \\
& \text { 1S-eat-CMP man } \\
& \text { 'I ate in front of [a] man.' }
\end{aligned}
$$

In sentence (21), the adposition is the word akuhi, and it occurs just after the determiner. In (22), there is no determiner, and now the adposition must occur just after the noun.

If the adposition is composed of two syllables or less, then preliminary stress data indicates the adposition does not receive independent stress (Michael 2003). In addition, an adposition of two syllables or less is not independently pronounceable from the word on its left. That is, in (21) a two-syllable adposition would not be separately pronounceable from the determiner, while in (22) it would not be independently pronounceable from the noun.

So, in returning to the possessums, the fact that possessums are stressable and independently pronounceable may have more to do with the fact that most nouns in Iquito consist of at least three syllables. The prediction would be that a monosyllabic or disyllabic possessum would behave like the two-syllable adpositions.

Finally, a clitic-like analysis would provide an explanation for why the possessum cannot have its own determiner or be modified by an adjective. As a clitic, the possessum is no longer functioning as a typical NP. In the process of cliticization, its functional capabilities have been reduced, and as such it cannot take complements nor can it serve as a complement to a determiner.

Therefore, my analysis is that the possessum behaves much like a clitic with regard to its position in a possessive construction. In a continuum between free forms, clitics, and affixes, the Iquito possessum would occur somewhere between a free form and a clitic ${ }^{4}$ :



\footnotetext{
${ }^{4}$ One might criticize this hypothesis from the general observation that bound morphemes tend to be closed classes, but the possessum is an open class. There are exceptions to this generalization. Noun incorporation is one well-known example of an open class becoming bound.
} 


\section{Problematic Analyses}

Before reaching the conclusion that the possessum is really a clitic-like element, I first propose and dispense with a number of other possible analyses. In the event that one proposes one of these analyses as an alternative to my hypothesis, I would like to discuss some of the problems I found inherent in these other approaches.

(24) Flawed analysis \#1: Possession in Iquito works by forming noun-noun compounds.

The first flawed analysis that is often suggested is that possession in Iquito works by creating noun-noun compounds. The examples in (1) and (2) showed that the possessive construction has no morphological marking but is just a sequence of two nouns. So, maybe the nouns are actually forming a compound. But this analysis falls apart when one considers the data from the irrealis constructions, in examples (11) and (12), where the verb intervenes between the two nouns. If the two nouns formed a compound, a verb should not be able to intervene between the two nouns.

Also, in a language which allows noun-noun compounds, one can often make a generalization for the language about which of the two nouns is the head. For example, we could say English forms right-headed noun-noun compounds, and that generalization would be true for every noun-noun compound in English. One cannot make such a generalization for Iquito, because the relative order of the two nouns is reversed when a determiner is present, which would mean the generalization would be wrong in half of all possible cases.

(25) Flawed analysis \#2: Why can't analyzing the determiner as a clitic account for the distributions in the data?

I am actually agnostic as to whether the determiner itself should be analyzed as a clitic. The determiner does play a crucial role in every instance of nominal discontinuity, and the properties and behavior of the determiner should be the subject of another paper. Nevertheless, even if the determiner were a clitic, that fact alone would not explain why the order of the possessor and possessum reverses when the determiner is present. That is, clitics are often capable of occurring in various locations in a sentence or phrase. This is one of the hallmark characteristics of a clitic. But clitics are not known for affecting the location of some other constituent in a sentence and forcing it to change its location. So, analyzing the determiner as a clitic would not account for the possessive construction.

(26) Flawed analysis \#3: Why can't a movement analysis of the possessor noun account for the data? 
Based on the contrast seen between (10) and (11), one may conclude that the determiner can move to a new position in place of the entire NP, and that perhaps one could then extend this kind of movement to explain the distribution of the NPs in a possessive construction. In this analysis, one would argue that perhaps in one case the determiner is moving to the left of the possessum, and when the determiner is not there, the possessor moves instead, as illustrated in the two tree diagrams below:

(27) Possession without a determiner

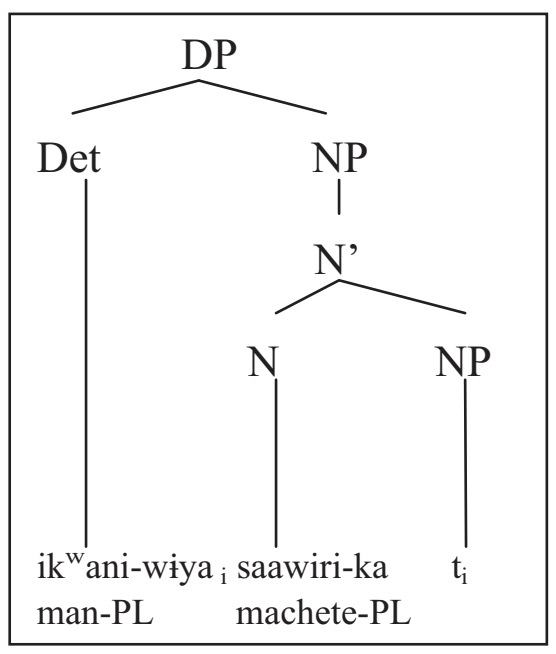

(28) Possession with a determiner

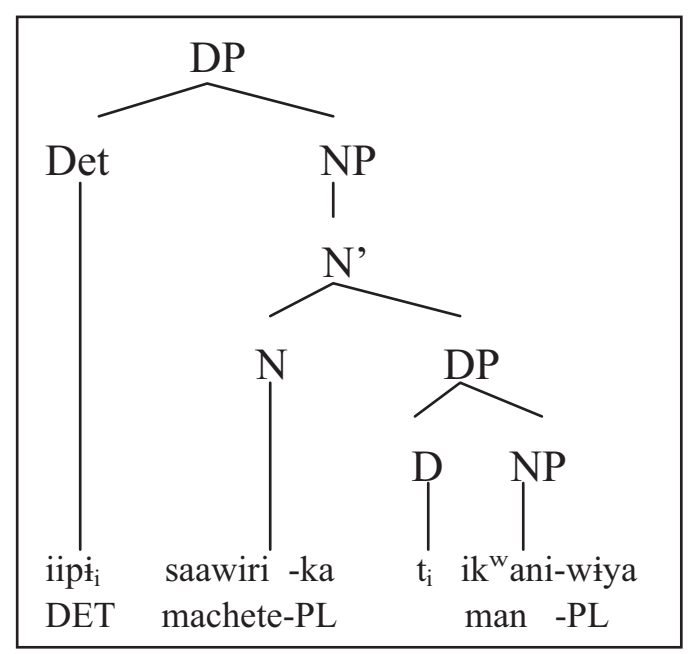

This movement now models the peculiar distribution of the NPs. A movement analysis of the possessor faces a number of important challenges. First, this analysis would need to show that a null DP exists in the case where there is no determiner. One needs the null DP so that the possessor has a place to go, so a movement analysis would have to show that a null functional head exists, and one should not get away with just making this an assumption. Second, an analysis of possession should also account for the distribution seen in adpositions. That is, given that adpositions and possessums have such similar distributions, any hypothesis of possession should either account for the distributions as well, or explain why the distribution of the adpositions should be treated differently. Under my analysis, both possessums and adpositions are argued to be clitic-like elements. Third, a movement hypothesis is not compatible with Generalization \#2. In looking at the irrealis constructions, when there was no possession involved, it was observed that the noun and its complements must remain together. ${ }^{5}$ Either the noun and all of its complements occurred to the right of the verb, or the noun and all of its complements occurred together to the left of the verb. The problem with a movement analysis and the manner in which X-bar theory works is that one of the two nouns must head the other. Either the

\footnotetext{
${ }^{5}$ The determiner, as the head of the noun phrase, is not a complement of the noun. Rather, the noun is a complement of the determiner.
} 
possessor heads the possessum, making the possessum a type of complement, or else the possessum heads the possessor, making the possessor a complement. Either way, a movement analysis would have to contradict the empirical observation set forth in Generalization \#2.

On the other hand, if the possessum were a clitic-like element attaching to the phrasal head, it would avoid these problems altogether and provide a more natural explanation for why the possessum seems to flaunt Generalization \#2. That is, phrasal contiguity is important when one is just making a syntactic analysis. Contiguity of a syntactic phrase is less important when one is essentially making a phonological analysis.

(29) Flawed Analysis \#4: Why can't analyzing the determiner as an anaphor coindexed with the possessor account for this data?

There are cases in which the demonstrative determiner can occur alone, without an NP complement, or it occurs in a typical NP argument position, but the constituent of the NP occurs extraposed at the end of the sentence. Some examples of this phenomenon are given below:

$$
\begin{aligned}
& \text { (30) ina maki -i } \\
& \text { Det sleep-INC } \\
& \text { 'That (one) is sleeping.' } \\
& \text { (31) iina maki -i amaka-hina ik }{ }^{\mathrm{w}} \text { ani } \\
& \text { Det sleep-INC road -DLS man } \\
& \text { 'That man is sleeping on the road.' }
\end{aligned}
$$

In (30), the determiner has no NP complement. In (31), the NP complement occurs extraposed at the end of the sentence. One could argue that in (31) the determiner is really functioning as a full NP anaphor and the noun $i k^{w} a n i$ is coindexed with the anaphor, thus explaining the nominal discontinuity without resorting to any movement. So, could one also argue that possession works by a similar sort of coindexation? Probably not. The nominal discontinuity seen above has two distinguishing properties: 1) the NP always occurs at the end of the clause, and 2) this kind of discontinuity is always defeasible. Thus, the sentence in (31) has a minimal pair (32) which is not discontinuous:

$$
\begin{aligned}
& \text { iina } \mathrm{ik}^{\mathrm{w}} \text { ani maki-i amaka-hina } \\
& \text { Det man sleep-INC road-DLS } \\
& \text { 'That man is sleeping on the road.' }
\end{aligned}
$$

The discontinuity seen in possession is never defeasible; it is always obligatory. In addition, the possessor is not extraposed at the end of the clause; it is just at the end of the phrase. 


\section{Possession and Cliticization in Iquito}

\section{Conclusion}

In conclusion, the possessum in Iquito should be analyzed as a type of clitic intermediate between an ideal free form and an ideal clitic. I make this argument because 1) it allows for a very concise generalization (\#1) to accurately describe where the possessum must occur, 2) its distribution shows it can select several different hosts which is a behavior consistent with clitics, 3) its distribution is identical to the distribution of adpositions, which are more clearly clitics themselves since adpositions of two syllables or less are unstressable and not independently pronounceable, 4) it would explain why the possessum cannot be modified since it is no longer fully a noun itself, and 5) obvious alternative analyses are all fundamentally flawed. ${ }^{6}$

\section{References}

Abney, Steven. 1987. The English noun phrase in its sentential aspect. Ph.D. diss., MIT.

Brown, Mark C. 2004a. Cliticization in Iquito. Presentation at the 9th Workshop on Structure and Constituency in the Languages of the Americas.

Brown, Mark C. 2004b. Topics in Iquito syntax: Word order, possession, and nominal discontinuity. M.A. thesis, University of Texas at Austin.

Delsing, Lars-Olaf. 1998. Possession in Germanic. In Artemis Alexiadou and Chris Wilder, eds., Possessors, Predicates and Movement in the Determiner Phrase. Amsterdam: John Benjamins.

Matthewson, Lisa. 1998. Determiner Systems and Quantificational Strategies: Evidence from Salish. The Hague: Holland Academic Graphics.

Michael, Lev. 2003. La fusión fonológica en iquito. Proceedings of the 1st Conference on the Indigenous Languages of Latin America.

Szabolcsi, Anna. 1994. The noun phrase. In The Syntactic Structure of Hungarian. Syntax and Semantics, vol. 27. San Diego: Academic Press.

Wiltschko, Martina. 2003. On the interpretability of tense on D and its consequences for case theory. Lingua 113:659-696.

Zwicky, Arnold M., and Geoffrey K. Pullum. 1983. Cliticization vs. inflection: English $n$ 't. Language 59:502-513.

Department of Linguistics, University of Texas at Austin

Calhoun Hall 501

1 University Station B5100

Austin, TX 78712

markbrown@mail.utexas.edu

\footnotetext{
${ }^{6}$ I thank Chris Beier, Lynda de Jong, Edinson Huamancayo, I-wen Lai, and Lev Michael for their collaboration in our fieldwork.
} 